\title{
Effect of diet supplementation with the addition of Saccharomyces cerevisiae upon stress response in slaughter lambs
}

\author{
Janina Sowińska ${ }^{1}$,Zenon Tański², Stanisław Milewski², Katarzyna Ząbek², Anna Wójcik ${ }^{1}$, \\ Przemysław Sobiech ${ }^{3}$, Josef Illek ${ }^{4}$
}

\begin{abstract}
${ }^{1}$ University of Warmia and Mazury in Olsztyn, Faculty of Bioengineering, Department of Animal Hygiene and Environment, ${ }^{2}$ Department of Sheep and Goat Breeding, ${ }^{3}$ Faculty of Veterinary Medicine, Department of Internal Diseases, Olsztyn, Poland

${ }^{4}$ University of Veterinary and Pharmaceutical Sciences, Faculty of Veterinary Medicine, Clinic of Ruminant Diseases, Brno, Czech Republic
\end{abstract}

Received April 20, 2015

Accepted May 2, 2016

\begin{abstract}
The study included 2 groups of lambs (GL): control (C) and experimental (E) which since day 11 of life was receiving an addition of dried Saccharomyces cerevisiae preparation. At the age of 100 days, 12 lambs from each group were weaned from mothers for 12-h pre-slaughter fasting, and transported to a slaughter house. Blood was sampled for analyses: before weaning from mothers (BST 1), before and after transport (BST 2 and 3). Blood samples were assayed for: values of neutrophils and lymphocytes, N:L (neutrophils to lymphocytes ratio), cortisol and glucose. After 24-h chilling of lamb carcasses, musculus longissimus dorsi was subjected to measurements of final acidity $\left(\mathrm{pH}_{24}\right)$ and colour (CIE Lab), and muscle samples were collected for evaluation of water absorption and shear force. The GL and BST had a significant effect on the N:L ratio. No significant differences were found in the cortisol concentration between groups of lambs. This indicator was significantly different in the analyzed blood sampling time $(P<0.01)$. In the entire period of pre-slaughter handling, in group $\mathrm{C}$ cortisol concentration increased $\times 8.5$, whereas in group $\mathrm{E}$ it increased $\times 4.3$ compared to the baseline value. In both groups, the study showed an increase $(P<0.01)$ in glucose concentration in BST 3 compared to BST 1 and BST 2. Meat of lambs from group E was characterized by lower $(P<0.05)$ values of $\mathrm{pH}_{24}$, WHC, SF, and indicator a*. The obtained results suggest the advisability of applying a preparation of dried brewer's yeast in rearing slaughter lambs in order to strengthen their immunity and to alleviate effects of pre-slaughter stress.
\end{abstract}

Sheep, yeast, pre-slaughter handling, blood indicators, meat quality

Pre-slaughter handling is a production stage of raw materials of animal origin that has important influence on the product quality. At this stage, animals are exposed to complex effects of many stress-inducing activities including: pre-slaughter fasting, loading on the means of transport, transport including its conditions and duration, and unloading at the slaughterhouse (Večerek et al. 2006; Miranda-de la Lama et al. 2010). In the case of suckling lambs, they are also exposed to weaning from mothers, which is an additional stress factor (Tadich et al. 2009; Ekiz et al. 2012a;b). The extent of stress response depends not only on technical and organizational conditions of pre-slaughter handling (Knowles et al. 1998; Fisher et al. 2005), but also on many other factors that affect biological defense structures of a body and the mode of animals' response to stress (Moberg 2000). Lower resistance of the body to stress factors may lead to depletion of muscle glycogen reserves before slaughter and result in greater body weight losses and deteriorated quality of meat (Kadim et al. 2006b). Hence, studies have been conducted for years on the alleviation of stress effects in various animal species. They concerned the use of pharmacological agents, vitamins, minerals, herbs or multi-component preparations (Wójcik et al. 2001; Ali and 
Al-Qarawi 2002; Ali et al. 2006). This direction of research is especially important in the case of slaughter animals, as procedures of pre-slaughter handling that will always be sources of stress practically cannot be eliminated. Considering the safety of food of animal origin, not all agents (especially anti-depressive drugs) may be used in practice (Ali and Al-Qarawi 2002; Ali et al. 2006).

In this respect, many authors (Collins and Ribson 1999; Milewski et al. 2007; Milewski 2009) demonstrated the advisability of supplementing animal diet with natural feed additives with pro- and prebiotic effects including, i.a. Saccharomyces cerevisiae yeast. Oligosaccharides contained in cell walls of Saccharomyces cerevisiae yeast, including mannans and $\beta-1,3 / 1,6-\mathrm{D}$-glucans, were shown to exert a stimulating effect on defense mechanisms of animal bodies (Collins and Ribson 1999; Li et al. 2005; Milewski et al. 2007).

The aim of this study was to determine the effect of diet supplementation with the addition of dried yeast Saccharomyces cerevisiae in the rearing period on the extent of stress response of lambs during pre-slaughter handling evaluated based on selected blood and meat quality indicators.

\section{Materials and Methods}

Animals and pre-slaughter handling

The study was conducted on 48 ram lambs from single parturitions, being the progeny of 3-year-old ewes of the Kamieniecka breed of sheep. The lambs were divided with the method of analogues according to the body weight criterion on the second day of life into 2 equal groups (GL): control (C) and experimental (E). For the entire 100-day rearing period lambs of both groups were kept with mothers in separate pens, but in the same room. Since day 11 of lambs' life, they were fed the same feed mixtures consisting of: prewilted silage from grasses and papilionaceous plants, meadow hay and CJ feed concentrate. Doses of the CJ feed concentrate were increased every $10^{\text {th }}$ day by $0.05 \mathrm{~kg} / \mathrm{lamb} /$ day, starting from the doses of $0.05 \mathrm{~kg} / \mathrm{lamb} /$ day at the age of 11-20 days. The experimental ram lambs were receiving an addition of Saccharomyces cerevisiae preparation (dried yeast Inter Yeast ${ }^{\circledR}$ S Leiber Sp. z o.o, Krośniewice, Poland) with CJ feed mixture in a dose of $50 \mathrm{~g} / \mathrm{kg}$ feed mixture. On completion of the 100-day rearing period, 12 lambs with a body weight similar to the mean body weight in a group (group $\mathrm{C}-25.16 \mathrm{~kg}$, group $\mathrm{E}-30.51 \mathrm{~kg}$ ) were selected from each group, weaned from mothers and subjected to $12-\mathrm{h}$ pre-slaughter fasting (with access to water). Next day in the morning, the animals were transported to the slaughter house in a vehicle adjusted for animal transport. The loading surface of the vehicle per one animal was $0.28 \mathrm{~m}^{2}$ and was consistent with guidelines stipulated by the Commission Regulation (EC) No. 1/2005 of 22 December 2004 on animal care during transport. The mean speed of the vehicle reached $50 \mathrm{~km} / \mathrm{h}$, and the transport took $80 \mathrm{~min}$. After electrical stunning, the lambs were slaughtered ca. $30 \mathrm{~min}$ after unloading.

The study was approved by the Local Ethics Commission for Experiments with Animals (Protocol no. 31/2009).

\section{Blood indices}

In order to examine defence mechanisms of the body and the extent of stress response to pre-slaughter handling, blood was sampled $\times 3$ from the jugular vein of the lambs: before weaning from mothers and pre-slaughter fasting (BST 1) as well as before (BST 2) and after transport to the slaughter house (BST 3). Blood films were prepared from whole blood (using Pappenhaim method) for leucogram preparation and for determination of the neutrophils to lymphocytes ratio (N:L). Hormonal and biochemical assays included determinations of cortisol and glucose concentrations in blood serum (Roche Cobas Integra 800 Analyser, Germany). Cortisol was assayed with the competitive method using a polyclonal antibody against cortisol (Test Elecsys Cortisol), whereas glucose was assayed using the reference enzymatic method with hexolinase. Analyses of blood indices were carried out at a specialist laboratory according to procedures approved in the certificate (Quality Manual Process 2: Laboratory Diagnostics part IH 1-12 and IB 1-32).

All activities linked with pre-slaughter handling and blood samples collection were performed by the same experienced group of persons. Time of manipulations involving lamb catching and weighing, and blood sampling both in the sheepfold and in the slaughter house reached $45-50 \mathrm{~s}$.

\section{Meat quality indicators}

After slaughter, lamb carcasses were chilled for $24 \mathrm{~h}$ at a temperature of $4{ }^{\circ} \mathrm{C}$. Afterwards, $\mathrm{m}$. longissimus dorsi was subjected to measurements of final acidity and colour, and muscle samples were collected for determinations of water binding capacity and tenderness. The acidity $\left(\mathrm{pH}_{24}\right)$ was measured with a portable meat $\mathrm{pH}$-meter, HI 99163 (Hanna Instruments, Germany) supplied with an FC electrode. Colour properties of meat were characterized in the CIE Lab system $\left(L^{*}, a^{*}\right.$ and $\left.b^{*}\right)$, with the reflection method using a MiniScan XE Plus 
apparatus (Hunter Associates Laboratory Inc., Reston, VA, USA) by direct 3-fold measurement of the crosssection area of the muscle at different sites.

For complex characteristics of water absorption of meat, analyses were conducted for: natural drip loss DL\% (Honikel 1998), water-holding capacity $\mathrm{cm}^{2}$, with Grau and Hamm method in modification by Pohja and Niniivaara (1957) and cooking loss CL\% (Honikel 1998).

The shear force (SF) was measured after heat treatment in a Warner-Bratzler chamber of an INSTRON 5542 apparatus with a measuring head $500 \mathrm{~N}$, on cylindrical samples (height $2 \mathrm{~cm}$, diameter $1.27 \mathrm{~cm}$ ) cut out from meat prepared accordingly to the method described by Honikel (1998).

\section{Statistical analysis}

Results were processed statistically by the STATISTICA 10.0 PL software. The analysis included characteristics of the examined blood and meat quality indicators $(\bar{x} \pm \mathrm{SE})$. In order to determine the effect of the addition of dried yeast (group C and E) and blood sampling time (BST 1, BST 2 and BST 3) on blood indices, a 2-way analysis of variance was conducted for cross orthogonal systems. The effect of yeast addition on meat quality indicators was determined using one-way analysis of variance in the orthogonal system. The significance of differences between mean values was determined using Duncan's test.

\section{Results}

Results of the analysed blood indices depending on the group of lambs and blood sampling time are presented in Table 1. No significant correlations were found between GL and BST for neutrophil counts, although those values tended to increase in both groups at successive stages of pre-slaughter handling. Lymphocyte counts decreased in both groups, and significant differences were noted in group C between BST 1 and 3. A significant effect of both the lamb group and the blood sampling period on mean values of the N:L ratio was observed. In the subsequent blood sampling times, no significant differences occurred in the mean N:L values between $C$ and $E$ groups. Only a slight tendency could be observed for lower N:L values in group E with dietary addition of dried brewer's yeast. After weaning lambs from mothers (BST 2) and after their transport to the slaughter house (BST 3), an increase occurred in the $\mathrm{N}: \mathrm{L}$ ratio in both groups. In group $\mathrm{E}$, this increase was not confirmed statistically, but in group $\mathrm{C}$, analyses confirmed the increase $(P<0.05)$ of this indicator in BST 3 compared to BST 1. It should also be noticed that in the entire period of pre-slaughter handling the $\mathrm{N}: \mathrm{L}$ ratio in group $\mathrm{C}$ increased 1.8-fold compared to the baseline values, whereas in group E this increase was smaller (1.4-fold). There were no significant differences in cortisol concentrations between groups of lambs, but the blood sampling time highly significantly differentiated the value of this indicator. Such a response of the pituitary-cortical-adrenal axis confirms the stress-bearing effect of pre-slaughter handling. The initial mean concentration of cortisol (BST 1) was significantly higher in group E, but the differences were not very high, only $0.2 \mu \mathrm{g} / \mathrm{dl}$ between the groups. In successive stages of pre-slaughter handling, its concentration was increasing in both groups and reached the highest value $(P<0.01)$ after transport to the slaughter house (BST 3$)$. In blood of control lambs, mean cortisol concentrations reached $0.23,0.56$, and $1.95 \mu \mathrm{g} / \mathrm{dl}$ in the successive blood sampling periods, whereas in blood of experimental lambs receiving the addition of dried yeast the respective values accounted for: $0.48,0.66$, and $2.06 \mu \mathrm{g} / \mathrm{dl}$. Compared to the baseline value (BST 1), this indicates a smaller increase in the concentration of this stress hormone in blood of lambs from group E, both in BST 2 and in BST 3. Considering the entire period of pre-slaughter handling, worthy of notice is that in group $\mathrm{C}$ analyses showed 8.5-fold increase and in group $\mathrm{E}$ with dietary addition of dried yeast only 4.3 -fold increase in cortisol concentration compared to the baseline value. The content of glucose in blood serum of lambs was highly significantly different depending on both GL and BST. In all blood sampling times (BST), higher glucose concentrations were reported in lambs from the experimental groups compared to control animals, however significant differences were confirmed only between BST 1 and BST 2. Both in group C and group E, analyses demonstrated a highly significant increase of glucose concentration in BST 3 compared 
to the value of this indicator noted in BST 1 and BST 2. These results show that both the weaning from mothers and the transport were stress-inducing factors to lambs. It needs to be noticed, however, that compared to the baseline value, a 1.6-fold increase and a lower 1.4-fold increase of glucose concentration occurred in groups $\mathrm{C}$ and $\mathrm{E}$, respectively, in the entire pre-slaughter handling period.

Table 1. Blood indicators depending on the group of lambs and blood sampling time ( $\bar{x} \pm \mathrm{SE})$.

\begin{tabular}{|c|c|c|c|c|c|c|c|c|c|}
\hline \multirow{3}{*}{$\begin{array}{l}\text { Blood } \\
\text { indicators }\end{array}$} & \multirow{3}{*}{$\begin{array}{c}\text { Blood } \\
\text { sampling } \\
\text { times (BST) }\end{array}$} & \multicolumn{4}{|c|}{ Group of lambs (GL) } & \multirow{3}{*}{ Anova $^{1}$} & \multirow{2}{*}{\multicolumn{3}{|c|}{$\begin{array}{l}\text { Significance of } \\
\text { main effects }\end{array}$}} \\
\hline & & \multicolumn{2}{|c|}{ Control (C) } & \multicolumn{2}{|c|}{ Experimental (E) } & & & & \\
\hline & & Mean & SE & Mean & SE & & GL & BST & BST G $x$ \\
\hline \multirow{4}{*}{$\begin{array}{l}\text { Neutrophils } \\
10^{9} / 1\end{array}$} & 1 & 2.99 & 0.40 & 2.41 & 0.26 & NS & & & \\
\hline & 2 & 3.57 & 0.47 & 2.52 & 0.25 & NS & NS & NS & NS \\
\hline & 3 & 3.66 & 0.50 & 2.79 & 0.27 & NS & & & \\
\hline & Anova $^{2}$ & NS & & NS & & & & & \\
\hline \multirow{4}{*}{$\begin{array}{l}\text { Lymphocytes } \\
10^{9} / 1\end{array}$} & 1 & NS 8.32 & 0.52 & 8.32 & 1.73 & NS & & & \\
\hline & 2 & 7.49 & 0.68 & 7.69 & 1.94 & NS & $*$ & NS & \\
\hline & 3 & $6.16^{\mathrm{b}}$ & 0.41 & 6.65 & 1.56 & NS & & & \\
\hline & Anova $^{2}$ & $*$ & & NS & & & & & \\
\hline \multirow{4}{*}{$\mathrm{N}: \mathrm{L}$} & 1 & $0.34^{\mathrm{b}}$ & 0.05 & 0.29 & 0.02 & NS & & & \\
\hline & 2 & 0.49 & 0.08 & 0.32 & 0.05 & NS & $*$ & $* *$ & NS \\
\hline & 3 & $0.59^{\mathrm{a}}$ & 0.05 & 0.42 & 0.05 & NS & & & \\
\hline & Anova $^{2}$ & $*$ & & NS & & & & & \\
\hline \multirow{4}{*}{$\begin{array}{l}\text { Cortisol } \\
\mu \mathrm{g} / \mathrm{dl}\end{array}$} & 1 & $0.23^{\text {by }}$ & 0.03 & $0.48^{b z}$ & 0.18 & $*$ & & & \\
\hline & 2 & $0.56^{\mathrm{b}}$ & 0.10 & $0.66^{\mathrm{b}}$ & 0.07 & NS & NS & $* *$ & NS \\
\hline & 3 & $1.95^{\mathrm{a}}$ & 0.15 & $2.06^{\mathrm{a}}$ & 0.32 & NS & & & \\
\hline & Anova $^{2}$ & $* *$ & & $* *$ & & & & & \\
\hline \multirow{4}{*}{$\begin{array}{l}\text { Glucose } \\
\mathrm{mmol} / \mathrm{l}\end{array}$} & 1 & $3.39^{\text {by }}$ & 2.74 & $3.89^{\mathrm{bz}}$ & 2.99 & $*$ & & & \\
\hline & 2 & $3.57^{\text {by }}$ & 2.02 & $4.43^{\mathrm{bz}}$ & 2.66 & $*$ & $* *$ & $* *$ & NS \\
\hline & 3 & $5.31^{\mathrm{a}}$ & 7.34 & $5.50^{\mathrm{a}}$ & 6.58 & NS & & & \\
\hline & Anova $^{2}$ & $* *$ & & $* *$ & & & & & \\
\hline
\end{tabular}

BST (blood sampling time): 1 - before weaning, 2 - before transport, 3 - after transport.

a,b Differences between the means of blood sampling time (BST) carrying different superscripts in the same column are significant.

y,z Differences between the means of group of lambs (GL) carrying different superscripts in the same line are significant.

${ }^{1}$ Anova: Significance of differences between groups of lambs for the same blood sampling time.

${ }^{2}$ Anova: Significance of differences between blood sampling times for the same group of lambs.

${ }^{*},{ }^{* *}$ Indicate significance at 0.05 and 0.01 , respectively.

NS: not significant.

Quality indicators of lamb meat obtained in this study were presented in Table 2. No significant differences were demonstrated between groups of lambs for drip loss (DL\%) and cooking loss (CL\%) and for colour variables $\mathrm{L}^{*}$ and $\mathrm{b}^{*}$. Compared to the meat of control animals, the meat of lambs from group $\mathrm{E}$ was characterized by lower $(P<0.05)$ values of $\mathrm{pH}_{24}$, drip area, shear force, and indicator a*. In our study, the meat of lambs from group $\mathrm{C}^{24}$ (with higher $\mathrm{pH}_{24}$ ) was characterized by significantly greater juice drip area $\left(\mathrm{cm}^{2}\right)$ and higher SF. Natural DL\% and CL\% were similar in both groups, although a small tendency could be observed for higher values of these indicators in group C. Results of our study demonstrated similar colour variables $\mathrm{L}^{*}$ and $\mathrm{b} *$ in meat of lambs from both groups. In contrast, significantly higher saturation with red colour $\mathrm{a}^{*}$ was noted in $\mathrm{C}$ group, which may have resulted from higher final $\mathrm{pH}$ of meat in this group. 
Table 2. Quality indicators of lamb meat depending on the group of lambs ( $\left.\bar{x}_{ \pm} \mathrm{SE}\right)$.

\begin{tabular}{lcccc}
\hline Specification & \multicolumn{4}{c}{ Group of lambs (GL) } \\
\cline { 2 - 5 } & \multicolumn{3}{c}{ Control (C) } & \multicolumn{3}{c}{ Experimental (E) } \\
\cline { 2 - 5 } & Mean & SE & Mean & SE \\
\hline $\mathrm{pH}_{24}$ & 5.74 & 0.01 & 5.60 & 0.03 \\
Drip loss, \% & 1.34 & 0.13 & 1.10 & 0.08 \\
WHC, cm & & 0.72 & $16.13^{\mathrm{b}}$ & 0.52 \\
Cooking loss, \% & $18.75^{\mathrm{a}}$ & 0.89 & 38.29 & 0.69 \\
Shear force, $\mathrm{N}$ & 39.82 & 1.02 & $22.77^{\mathrm{b}}$ & 1.08 \\
Colour variables: & $26.54^{\mathrm{a}}$ & & & \\
$\mathrm{L}^{*}$ & & 0.74 & 47.50 & 0.86 \\
$\mathrm{a}^{*}$ & 45.96 & 0.14 & $11.17^{\mathrm{b}}$ & 0.21 \\
$\mathrm{~b}^{*}$ & $12.40^{\mathrm{a}}$ & 0.26 & 14.47 & 0.25 \\
\hline
\end{tabular}

${ }^{a, b}$ Differences between the means of group of lambs (GL) in the same line are significant at 0.05 .

\section{Discussion}

Many investigations addressed the stress-inducing effects of pre-slaughter handling (including lambs weaning from mothers, pre-slaughter fasting, and rest in lairage) and of its significant element - namely transport including its conditions, duration and season of the year (Knowles et al. 1998; Fisher et al. 2005; Sowińska et al. 2006; Kadim et al. 2006b; Bórnez et al. 2009; Miranda-de la Lama et al. 2010; Ekiz et al. 2012a,b).

Stress factors cause an increase in the contribution of neutrophils and a decrease in the contribution of lymphocytes in the leucocyte population, thereby causing an increase in the N:L ratio (Schaefer et al. 1997). Based on an increase in the N:L ratio, Miranda-de la Lama et al. (2010) stated that a stress factor to slaughter lambs was not only longer period of staying at the classification centre but also high temperatures in the summer season. In turn, Ekiz et al. (2012a) demonstrated a significant increase in N:L ratio after 75-min transport of 135-day ram lambs to a slaughter house. Results of our study also demonstrated the stress-inducing effect of pre-slaughter handling. It should, however, be emphasized that compared to group $\mathrm{C}$, in group $\mathrm{E}$ the values of $\mathrm{N}: \mathrm{L}$ ratio were lower and its increase was smaller in the successive stages of pre-slaughter handling. It may be indicative of lesser stress susceptibility of the lambs administered the addition of dried yeast preparation. This is consistent with the results of a study by Milewski (2009), who demonstrated a significant increase $(P<0.01)$ in the percentage of lymphocytes and a tendency for lower percentage of neutrophils in blood of lambs receiving the addition of dried yeast. According to this author, it is indicative of a better immunological status of animals ingesting yeast preparations.

Cortisol is an important indicator while determining the stress level in animals, because it reflects the body response depending on the intensity of the stress factor (Strzelec et al. 2011; Kadim et al. 2009). Kadim et al. (2006a) demonstrated a several-fold increase in cortisol concentration after 2-h transport in three breeds of goats, whereas in the case of non-transported animals the increase in this hormone was very small. The results of our study also demonstrated the stress-inducing effect of pre-slaughter handling. Mean initial cortisol concentrations (BST 1) were significantly higher in group E, which could reflect the activation of the sympathoadrenal system of lambs fed a prebiotic-supplemented diet that enhanced their immune responses to stress. It should also be noted that in both groups of lambs, cortisol concentrations at BST 1 were similar to the values determined before stress exposure, and reported by other authors, e.g. $0.27 \mu \mathrm{g} / \mathrm{dl}$ (Ekiz et al. 2012a), 
$0.71 \mu \mathrm{g} / \mathrm{dl}$ (Kadim et al. 2009), $2.7 \mu \mathrm{g} / \mathrm{dl}$ (Tadich et al. 2009). It should, however, be emphasized that compared to group $\mathrm{C}$, the increase in cortisol concentration in group $\mathrm{E}$ was smaller in the successive stages of pre-slaughter handling. These results point to the beneficial effect of applying the preparation of dried brewer's yeast, because the experimental lambs were characterized by lower susceptibility to stress, as confirmed by values of the $\mathrm{N}: \mathrm{L}$ ratio.

Changes in the blood content of glucose in lambs as a response to stress induced by preslaughter handling were also demonstrated by many other authors (Ali et al. 2006; Bórnez et al. 2009; Tadich et al. 2009; Ekiz et al. 2012a). Ali et al. (2006) showed an increase $(P<0.05)$ in glucose concentration after 2 -h transport of lambs. These authors claim that hyperglycaemia observed during stress may be a secondary effect of hypercortisolaemia or may result from enhanced glucose production in the liver, thus reflecting enhanced activity of the sympathetic-adrenal system.

Likewise, a significant effect of 75-min transport on the glucose concentration increase in 135-day lambs was reported by Ekiz et al. (2012a); whereas in the successive stages of pre-slaughter handling these authors demonstrated an opposite response of the lambs which depended on the length of rest before slaughter. In lambs allowed to rest for 30 min after transport the content of glucose was increasing till the moment of slaughter, whereas in animals allowed to rest for $18 \mathrm{~h}$ the content of glucose was maintained at a similar level to that assayed after the transport. Tadich et al. (2009) showed similar glucose concentrations both at the farm and after 48-h transport and suggested that transport-preceding procedures at the farm such as catching and weaning from mothers, and uploading may be more stress-inducing than transport itself. The higher reference glucose concentrations observed in our study in lambs receiving the prebiotic, could be indicative of their greater energy reserves involved in the stress response. It should be noted that prebiotic supplementation contributes to improvements in metabolic processes leading to glucose synthesis. Throughout the pre-slaughter period, the increase in glucose concentrations was lower in group E, thus suggesting that lambs fed dried yeasts were less sensitive to stress, which corresponds to the values of $\mathrm{N}: \mathrm{L}$ ratio and cortisol concentrations.

The final $\mathrm{pH}$ of meat is the main determinant of its quality, because it influences the meat water holding capacity, colour, and tenderness. The final acidity depends on co-effects of many factors occurring during pre-slaughter handling that influence glycogen reserves in muscles and the rate of glycolytic transformations (Thompson 2002). The pre-slaughter stress causes depletion of glycogen reserves in muscles before slaughter, which results in insufficient acidification of muscles after slaughter, which in turn leads to increased $\mathrm{pH}$ of meat (Apple et al. 1995; Kannan et al. 2003). Results of investigations conducted by many authors demonstrated a significant effect of various stress stimuli on final $\mathrm{pH}$ value. Kadim et al. (2006a) reported that 2-h transport of goats had a significant impact upon an increase in the final acidity, whereas Kadim et al. (2009) showed higher final pH of meat of lambs slaughtered after 3-h transport compared to the non-transported lambs. In turn, Apple et al. (2005) demonstrated that also stress linked with sheep immobilization was causing significantly higher $\mathrm{pH}_{24}$ compared to meat of non-stressed sheep, whereas Ruizde la Torre et al. (2001) reported that 4-h transport of lambs on an uneven (bumpy) road resulted in a significant increase in meat $\mathrm{pH}_{\mathrm{f}}$ compared to meat of lambs transported on a smooth road. The mean $\mathrm{pH}_{24}$ value of meat obtained in our study was higher $(P<0.05)$ in the group of control lambs. Though the value of this indicator was within the range of 5.5-5.8 in both groups, thus indicating good quality of meat, the lower $\mathrm{pH}$ in the experimental group may indicate a positive effect of lamb diet supplementation with brewer's yeast on alleviation of stress response effects.

Bond et al. (2004) demonstrated that muscles of stressed lambs had a significantly higher drip loss at higher final pH. Also Kadim et al. (2006a) reported a higher WHC in 
transported goats. Contrary to the above studies, Kadim et al. (2009) showed that meat of lambs transported for $3 \mathrm{~h}$ had a significantly lower drip area compared to the nontransported lambs. Meat of the transported lambs was also characterized by significantly lower CL\%. Likewise Apple et al. (1995) demonstrated lower CL\% in meat of stressed lambs.

In our study, a higher SF of meat $(P<0.05)$ was shown in group $\mathrm{C}$, which points to higher hardness of meat, compared to the group of lambs receiving dietary addition of prebiotic. Investigations conducted by many authors demonstrated that pre-slaughter stress might affect deterioration of meat tenderness. For instance, Kadim et al. (2009) reported that meat of sheep transported for $3 \mathrm{~h}$ had a significantly higher SF compared to meat of non-transported animals. Similar results were achieved after 2-h transport of goats (Kadim et al. 2006a) and in lambs slaughtered after 75-min transport and short rest before slaughter (Ekiz et al. 2012a). In turn, Apple et al. (1995) demonstrated a lower SF of meat of stressed lambs compared to non-stressed lambs, whereas Kannan et al. (2003) did not demonstrate any differences in meat tenderness between transported and non-transported goats.

Many authors demonstrated that the darker colour of lamb meat was due to various stress factors (Apple et al. 1995; Bond et al. 2004). Ruiz-de la Torre et al. (2001) report that transport of 10- to 12-week-old lambs on an uneven road caused a significant increase in their meat saturation with red colour. In turn, Kadim et al. (2006a) stated that compared to non-transported goats, meat of goats transported for $2 \mathrm{~h}$ was darker, more red and less yellow (lower values of $\mathrm{L}^{*}$ and $\mathrm{b}^{*}$, and higher value of $\mathrm{a}^{*}$ ). Whereas Ekiz et al. (2012a) did not demonstrate any significant differences in colour indicators of lamb meat irrespective of pre-slaughter procedures (transport, no transport, different time of pre-slaughter rest).

This study confirmed that even with great care taken for animal welfare during preslaughter handling, slaughter lambs are exposed to many stress-inducing activities.

Results of this study and findings of other authors suggest that even under optimal technical and organizational conditions of pre-slaughter handling, many physical, physiological and psychical stress stimuli do occur that diminish the welfare of animals and deplete their bodily reserves. It was also shown that not only the atmospheric conditions and transport duration are important but also various pre-slaughter practices linked with the age at which lambs are weaned from their mothers or with providing rest before slaughter and the duration of rest. The results achieved demonstrated the usability of dietary addition of dried brewer's yeast Saccharomyces cerevisiae - a natural feed additive with prebiotic character, for alleviating the stress response and its effects. Beta-glucans and mannanooligosaccharides present in cell walls of yeast exhibiting immunomodulatory action alleviated the intensification of stress response evaluated based on blood indicators.

\section{References}

Ali BH, Al-Qarawi AA 2002: An evaluation of drugs used in the control of stressful stimuli in domestic animals: a review. Acta Vet Brno 71: 205-216

Ali BH, Al-Qarawi AA, Mousa HM 2006: Stress associated with road transportation in desert sheep and goats, and effect pretreatment with xylazine or sodium betaine. Res Vet Sci 80: 343-348

Apple JK, Dikeman ME, Minton JE, McMurphy RM, Fedde MR, Leith DE, Unruch JA 1995: Effects of restraint and isolation stress and epidural blockade on endocrine and blood metabolite stress, muscle glycogen and incidence of dark-cutting Longissimus muscle of sheep. J Anim Sci 73: 2295-2302

Bond JJ, Can LA, Warner RD 2004: The effect of exercise stress, adrenaline injection and electrical stimulation on changes in quality attributes and proteins in semimbranosus muscle of lamb. Meat Sci 68: 469-477

Bórnez R, Linares MB, Vergara H 2009: Haematological, hormonal and biochemical blood parameters in lambs: Effect of age and blood sampling time. Livest Sci 121: 200-206

Collins MD, Ribson GR 1999: Probiotics, prebiotics and symbiotics: approaches for modulating the microbial ecology of the gut. Am J Clin Nutr 69: 1052-1057 
Ekiz B, Ekiz EE, Kocak O, Yalcintan H, Yilmaz A 2012a: Effect of pre-slaughter management regarding transportation and time in lairage on certain stress parameters, carcass and meat quality characteristics in Kivircik lambs. Meat Sci 90: 967-976

Ekiz B, Ekiz EE, Yalcintan H, Kocak O, Yilmaz A 2012b: Effects of suckling length (45, 75 and 120 d) and rearing type on cortisol level, carcass and meat quality characteristics in Kivircik lambs. Meat Sci 92: 53-61

Fisher A, Steward DM, Duganzich DM, Tacon J, Matthews LR 2005: The effects of stationary periods and external temperature and humidity on thermal stress conditions within sheep transport vehicles. New Zeal Vet J 53: 6-9

Honikel KO 1998: Reference methods for the assessment of physical characteristics of meat. Meat Sci 49: 447-457

Kadim IT, Maghoub A, Al-Kindi W, Al-Marzzoqui W, Al-Saqri NM 2006a: Effects of transportation at high ambient temperatures on physiological responses, carcass and meat quality characteristics of the breeds of Omani goats. Meat Sci 73: 626-634

Kadim IT, Maghoub A, Al-Kindi W, Al-Marzzoqui W, Al-Saqri NM, Almaney M, Mahmoud IY 2006b: Effects of transportation at high ambient temperatures on physiological responses, carcass and meat quality characteristics in two age groups of Omani sheep. Asian Australas J Anim Sci 20: 424-431

Kadim IT, Maghoub O, Al-Marzooqi W, Khalaf S, Al-Sinawi SSH, Al-Amri IS 2009: Effects of transportation during the hot season and low voltage electrical stimulation on histochemical and meat quality characteristics of sheep longissimus muscle. Livest Sci 126; 154-161

Kannan G. Kouakou B, Terrill TH, Gelaye S 2003: Endocrine, blood metabolite and meat quality changes in goats as influenced by short-term, pre-slaughter stress. J Anim Sci 81: 1450-1457

Knowles TG, Warris PD, Brown SN, Edwards JE 1998: Effects of stocking density on lambs being transport by road. Vet Rec 144: 687-692

Li J, Xing J, Li D, Wang X, Zhao L, Lv S, Huang D 2005: Effects of beta-glucan extracted from Saccharomyces cerevisiae on humoral and cellular immunity in weaned piglets. Arch Anim Nutr 59: 303-312

Milewski S, Wójcik R, Małaczewska J, Trapkowska S, Siwicki AK 2007: Effect of $\beta$-1,3/1,6-D-glucan on meat performance and non-specific humoral defense in lambs. Med Wet 63: 360-363

Milewski S 2009: Effect of yeast preparations Saccharomyces cerevisiae on meat performance traits and blood hematological indices in sucking lambs. Med Wet 65: 51-54

Miranda-de la Lama GC, Rivero L, Chacón G, Garcia-Belenguer S, Villarroel M, Maria GA 2010: Effect of the pre-slaughter logistic chain on some indicators of welfare in lambs. Livest Sci 128: 52-59

Moberg GP 2000: Biological response to stress: implication for animal welfare. In: Moberg GP, Mench JA (Eds): The Biology of Animal Stress. Wallingford, CAB International, pp.1-21

Pohja MS, Niinivaraa FP 1957: Die Bestimmung der Wasserbindung des Fleischesmittels der Konstantdruckmethode. Fleischwirtschaft 9: 193-195

Ruiz-de la Torre JL, Velarde A, Diestre A, Gispert M, Hall SJG, Broom DM, Manteca X 2001: Effects of vehicle movements during transport on the stress responses and meat quality if sheep. Vet Rec 148: 227-229

Schaefer AL, Jones SD, Stanley RW 1997: The use of electrolyte solutions for reducing transport stress. J Anim Sci 75: 258-265

Sowińska J, Brzostowski H, Tański Z, Lisowska J 2006: Stress reaction of lambs to weaning and short transport to slaughterhouse regards to the breed and age. Med Wet 62: 946-948

Strzelec K, Kankofer M, Pietrzak S 2011: Cortisol concentration in the saliva of horses subjected to different kinds of exercise. Acta Vet Brno 80: 101-105

Tadich N, Gallo C, Brito M, Broom DM 2009: Effects of weaning and $48 \mathrm{~h}$ transport by road and ferry on some blood indicators of welfare in lambs. Livest Sci 121: 132-136

Thompson J 2002: Managing meat tenderness. Meat Sci 62: 295-308

Wójcik A, Sowińska J, Iwańczuk-Czernik K 2001: Body weight losses, mechanical damage and meat quality characteristics in slaughter turkeys receiving vitamin-mineral components before pre-slaughter handling. Pol J Food Nutr Sci 51: 244-247

VečerekV, Malena M, Malena JM, Voslářová E, Bedáňová I 2006: Mortality in dairy cows transported to slaughter as affected by travel distance and seasonality. Acta Vet Brno 75: 449-454 